\title{
27 THE CORPORATE DIGITAL DIVIDE BETWEEN SMALLER AND LARGER FIRMS
}

\author{
Nava Pliskin \\ Ben-Gurion University of the Negev \\ Beer-Sheva, Israel \\ Margi Levy \\ Warwick Business School \\ Coventry, U.K. \\ Tsipi Heart \\ University College Cork \\ Cork, Ireland \\ Brian O'Flaherty \\ University College Cork \\ Cork, Ireland \\ Paul O'Dea \\ Select Strategies \\ Ireland
}

\section{INTRODUCTION/BACKGROUND}

Investments by large corporations in information and communication technologies (ICTs) is steadily growing, comprising on average 4 percent of corporate revenues, with about two-thirds of the ICT investment directed to operations and only about a third to strategic opportunities (META 2005). While true for larger organizations (these figures were calculated based on data gathered from 1,907 organizations with more than $\$ 1$ billion in revenue), the picture is somewhat different for small or medium-sized enterprises (SMEs), with between 10 and 250 employees, most of which invest a much smaller proportion of their revenue in ICT. For example, Heart et al. (2001) found that hospitality SMEs invest only about 1 percent of revenue in ICT. In their constant struggle to reduce costs, SMEs invest in mandatory ICT operations and their utilization of ICT is often inefficient.

Please use the following format when citing this chapter:

Pliskin, N., Levy, M., Heart, T., O'Flaherty, B., and O'Dea, P., 2006, in IFIP International Federation for Information Processing, Volume 208, Social Inclusion: Societal and Organizational Implications for Information Systems, eds. Trauth, E., Howcroft, D., Butler, T., Fitzgerald, B., DeGross, J., (Boston: Springer), pp. 413-417. 
Larger organizations can opt for outsourcing arrangements to reduce IT operational costs (IT outsourcing expenditure was up 5 percent from 2004 to 2005 for large companies). However, for many SMEs, outsourcing is not an option for at least three reasons. First, SMEs do not have the financial resources to pay outsourcing fees. Second, SMEs often do not recognize the need for continual refreshment of their ICT provision (Ballantine et al. 1998). Third, the relatively underdeveloped ICT accounts of SMEs are unattractive for the major ICT outsourcers. Earlier predictions that software might soon become a remotely accessed, cheap commodity are yet unfulfilled, with even SMEs unwilling to pioneer with remote access via application service providers (ASPs) to their mission-critical applications (Heart and Pliskin 2002).

Consequently, there is evidence about SMEs neither utilizing ICT strategically, to gain competitive edge, nor maximizing business value of IT (Levy et al. 2002). This puts SMEs at a strategic disadvantage relative to larger organizations. SMEs, with their focus on business survival, form an underprivileged sector in terms of ICT usage. It thus makes sense to note, and discuss in this panel, the corporate digital divide between larger (haves) and smaller (have-nots) enterprises, which resembles the digital divide at the individual level, where those underprivileged parts of the population have no access to the benefits acquired by ICT usage.

An additional element of the corporate digital divide is the lack of ICT training for employees (who represent 65 percent of the workforce). This is likely to limit the benefits at both the individual and firm level of ICT usage in SMEs. The panel has relevance for the conference theme not only because a corporate digital divide does exists but also because the two types of digital divide are closely linked.

\section{PANEL CONTENT AND ORGANIZATION}

Nava Pliskin will introduce the subject and moderate. It is now evident from both research and practice that information technology plays a critical role in the competitive position of firms. Effective and efficient IT utilization is required in order to achieve market visibility, marketing strength and customer intimacy, as well as cost-effective business processes. Whereas larger organizations have invested millions in implementing enterprise-wide ERP, CRM, SRM, and DW systems, smaller organizations can neither afford the cost nor the expertise required for acquiring ERP utilization competencies. Although both SAP and Oracle now offer cheaper packages for middle-sized firms, these packages still require an up-front investment of $\$ 300,000$ to $\$ 500,000$, plus a need to employ expensive internal experts. For a smaller firm struggling to win or at least survive in a competitive market, such an investment is still unachievable. Developing customized applications is likewise unaffordable, since such organizations cannot allocate the resources required to smoothly complete a software development project. Consequently, organizations such as national hotel chains or restaurants often end up with a fragmented, underutilized application suite, procured off-the-shelf based on affordability considerations, rather than on genuine strategic and business-oriented IT planning. This situation reflects a digital divide between the larger and smaller organizations, placing a serious barrier for the latter to successfully compete and thrive in turbulent markets. 
Margi Levy will present the strategic struggle of SMEs in ICT adoption. Research suggests that there are distinct approaches to IS investment in SMEs depending on the relative dominance of customers and the strategic focus of the firm. Customer dominance is dependent on the firm's size and the competitiveness of the market. Smaller firms and firms with few customers have high dependence. As firms grow and the customer base declines, the dependency is reduced. Customer dependency can influence IS investment decisions in SMEs.

The owner is critical in determining the strategic focus of the firm. The owner's influence depends upon several factors: (1) knowledge about the potential for business value from information systems is a key influence on adoption of strategic IS; (2) the desire to grow the business; and (3) recognition that there is a need for a strategy to manage growth. The approach taken to strategic growth determines whether owners view IS investment as a cost to the business, a necessary evil that requires minimal resources, or as adding value to achieving strategic objectives.

This leads to the identification of four scenarios for strategic IS investment in SMEs and the identification of different strategic management perspectives. Research suggests that firm growth may change strategic IS investment while those SMEs that do not plan for growth are in danger of ossification.

Tsipi Heart will present the status of application hosting as a plausible, more affordable ICT source for SMEs. Research shows that firms invest on average 60 to 70 percent of their annual IT budget on maintenance and operations; thus only about a third of the budget is actually invested in enhancing IT to better cater to changing market requirements. Firms now strive to reduce IT expenses and total cost of ownership (TCO), outsourcing being the major solution adopted by many. While reliable and trustworthy multinational vendors, such as IBM and EDS would compete on such large accounts, they would often refrain from taking on IT operations of smaller firms, assuming it infeasible. Thus, smaller organizations either end up with lower-tier, less reliable vendors, usually outsourcing to multiple vendors, or keep their IT operation internal. IT remote hosting in various forms is recently emerging as a viable sourcing option for the smaller organization. Recent research shows that first-wave vendors did not exhibit the characteristics essential for adopting the ASP optino required by decision makers in SMEs. Although the first wave of application service providers (ASPs) did not succeed in establishing a stable and value-adding business model, second-generation ASPs are now emerging. The difference between the offerings of the second wave ASPs and their earlier counterparts will be discussed, leading to the assumption, supported by Carr (2005), that Web hosting might be a new, feasible IT sourcing option for SMEs, perhaps leading to bridging the digital divide between these firms and their larger competitors.

Brian O'Flaherty will speak about innovation in SMEs. In the current, turbulent international market, innovation is a common strategy adopted by SMEs in order to keep abreast of competition and enter new markets. These innovative approaches can involve new product, service or business model strategies and, if implemented successfully, smaller companies can disrupt larger incumbent market leaders. While studies show that smaller firms are less likely to adopt IT in supporting their business, research also indicates that smaller firms are more innovative than their larger counterparts, but they also adopt different innovation processes in pursuit of differentiation. This provides a 
contradiction and clear evidence of a digital divide, where SMEs are slow to adopt technology, but are required, by their nature, to innovate.

Paul O'Dea will describe the situation of IT adoption and IT selling by Irish SMEs. The continous state of rapid evolution and dynamic market conditions that are the hallmarks of high technology places severe stress on companies striving for survival, success, and ultimately hyper-growth. Clarity of purpose, a laser-like focus on execution, and an uncluttered vision of implementation strategies and tactics are essential ingredients in defining the recipe for achievement. If ambiguity or fuzziness exists, or if the correct offering is not being provided to the right customers through the optimum sales and marketing channels, failure is a certainty. Information technology is an enabler in monitoring essential activities leading start-ups to the required growth, yet these tools are often unaffordable or too complex for smaller start-ups. Paul, who is familiar with the Irish and global start-ups market, will describe how these emerging firms utilize IT as a tool leading to success.

\section{ABOUT THE PANELISTS}

Nava Pliskin (pliskinN@bgu.ac.il) is in charge of the Information Systems programs at the Department of Industrial Engineering and Management Ben-Gurion University in Israel. Previously she was a Thomas Henry Carroll Ford Foundation Visiting Associate Professor at the Harvard Business School. She received her Ph.D.and S.M.degrees from Harvard University. Her research, focused on longitudinal analysis of IS impacts at the global, national, organizational, and individual levels, has been published in such journals as IEEE Transactions on Engineering Management, ACM Transactions on Information Systems, The Information Society, Communications of the ACM, Decision Support Systems, Information \& Management, and Data Base.

Margi Levy (Margi.Levy@wbs.ac.uk) is a senior lecturer and a member of the Operational Research and Information Systems Group at Warwick Business School. She has an M.Sc., B.Sc., and PGME degrees. Margi joined the Warwick Business School as a lecturer in 1992. Formerly she lectured on information systems at Curtin University of Technology in Western Australia. Before that, she worked as an IS consultant with Coopers and Lybrand in Western Australia, and also worked for various firms in London as a business systems analyst. Her research interests are e-business strategies for SMEs; IS strategy for SMEs; e-networks for SMEs; IS success; IT adoption in SMEs. She has published in such journals as Information Resource Management, European Journal of Information Systems, Small Business Economics, Journal of Information Technology, and Information and Management. She is the coauthor, with Philip Powell, of Strategies for Growth in SMEs: The Role of Information and Information Systems, recently published by Butterworth-Heinemann..

Tsipi Heart (t.heart@ucc.ie) is a lecturer in the Business Information Systems Department at University College Cork, Ireland, where she teaches IT management related courses. She has received her Ph.D. at the Department of Industrial Engineering and Management of Ben-Gurion University of the Negev in Israel, after serving as CIO and a consultant in Israeli organizations. Tsipi's research focuses on IT implementation in small and medium size enterprises, IT strategy and management, IT innovation and 
adoption, cultural differences in IT usage, and application service providers. Her work has been published in such journals as Information Technology and Tourism, International Journal of Hospitality Information Technology, Communications of the AIS, INFOR, and Journal of Information Technology Theory and Application.

Brian O'Flaherty (b.oflaherty@uccc.ie) is a member of faculty in the Department of Business Information Systems at University College Cork. Having initially worked in the software industry, he has been teaching in UCC for over 15 years. He recently completed his doctoral research in Management Science at the University of Strathclyde, Glasgow. He is actively involved in research commercialization training initiatives within UCC and has secured EI funding for an enterprise start-up program specifically for academic and research staff. In collaboration with colleagues in the Business Faculty, he initiated a research commercialization business module, which will be available to every doctoral student in the University in the next academic year. His areas of interest include information infrastructures, spatial data infrastructures, innovation and software. His work has been presented in conferences such as ECIS and PACIS.

Paul O'Dea (bpodea@selectstrategies.com) is CEO of Select Strategies, Ireland. He achieved extraordinary success as a founder of a leading international banking software company, prior to its acquisition by one of the world's largest application software companies. He has worked with, and mentored, sales organizations in the United States, Europe, Australia, and Asia. He has led numerous high technology companies through early market development, sales process and execution, and international growth. He is also a guest lecturer in international competitive strategy in the Smurfit Business School, Dublin, one of the world's leading business schools.

\section{References}

Ballantine, J., Levy, M., and Powell, P. "Evaluating Information Systems in SMEs: Issues and Evidence," European Journal of Information Systems (7), 1998, pp. 241-251.

Carr, N. "The End of Corporate Computing," MIT Sloan Management Review (46:3), 2005, pp. 66-73.

Heart, T., and Pliskin, N. "Business-to-Business eCommerce of Information Systems: Two Cases of ASP-to-SME eRental," INFOR (40:1), 2002, pp. 23-34

Heart, T., Pliskin, N., Shechtman, E., and Reichel, A. "Information Technology in the Hospitality Industry: The Israeli Scene and Beyond," Information Technology \& Tourism (4:1), 2001, pp. 41-64.

Levy, M., Powell, P., and Yetton, P. "The Dynamics of SME Information Systems," Small Business Economics (19), 2002, pp. 341-354.

META Group. Worldwide IT Benchmark Report, 2005. 